\title{
AVALIAČÃO QUALITATIVA DOS PERFIS FITOQUIIMICOS DE EXTRATOS DE MACAÍBA (Acrocomia aculeata) OBTIDOS POR DIFERENTES TÉCNICAS DE EXTRAÇÃO
}

\author{
A. D. PEÇANHA ${ }^{1}$, M.R.A. FERREIRA ${ }^{2}$, M.A.M. GALVÃO ${ }^{2}$, L.A.L. SOARES ${ }^{2}$, L. \\ DANIELSKI $^{1}$ \\ Universidade Federal de Pernambuco - UFPE \\ ${ }^{1}$ Departamento de Engenharia Química, Laboratório de Combustíveis (LAC). \\ ${ }^{2}$ Departamento de Ciências Farmacêuticas, Laboratório de Farmacognosia (LF). \\ E-mail para contato: andreadacalpeanha@yahoo.com.br
}

\begin{abstract}
RESUMO - A composição e qualidade de fitoquímicos estão diretamente ligadas à forma de extração utilizada em sua obtenção. Industrialmente uma série de técnicas é empregada para este fim e as mais comuns são as que utilizam solventes orgânicos associados ao aumento de temperatura do sistema. Estas técnicas podem degradar compostos e ainda apresentar resquícios de solvente no produto final. O objetivo deste estudo foi avaliar os perfis fitoquímicos do extrato de polpa de macaíba (A. aculeata) obtidos convencionalmente por meio de extração em Soxhlet e com o equipamento ASE 350 (Accelerated Solvent Extractor) utilizando hexano como solvente, e também por via supercrítica utilizando $\mathrm{CO}_{2}$. A extração supercrítica (ESC) foi conduzida com pressão fixa em 100 bar e temperatura de $40^{\circ} \mathrm{C}$. Os perfis foram obtidos por cromatografia gasosa e a maior seletividade do $\mathrm{CO}_{2}$ foi comprovada.
\end{abstract}

\section{INTRODUÇÃO}

Geralmente, o processo de obtenção de bioativos de matrizes vegetais envolve uma série de etapas, por meio das quais se realiza a separação das substâncias de interesse. Convencionalmente, as técnicas de extração e fracionamento de extratos vegetais apresentam pontos desfavoráveis, como o uso de elevadas temperaturas, presença de resíduos tóxicos no produto final e a possibilidade de contaminação ambiental. Atualmente, o maior rigor das leis ambientais aliado à demanda de produtos de melhor qualidade, tem impulsionado a busca por tecnologias diferenciadas.

De acordo com Santos (2012), dentre os novos métodos de extração apresentados em literatura, o que utiliza fluido supercrítico tem se tornado foco de estudos pelas vantagens apresentadas quando comparado a outras técnicas, destacando-se o uso de temperaturas brandas e a completa separação do soluto/solvente obtida pela simples descompressão do sistema. Neste contexto, o uso de fluidos supercríticos nos processos mencionados é uma alternativa promissora, sobretudo nas indústrias de alimentos, farmacêutica e de química fina, onde a busca por produtos de maior valor agregado é incessante.

Nos processos de extração supercrítica a matriz vegetal de interesse é inserida em um extrator onde circula uma corrente de fluido supercrítico (solvente) em condições de pressão, temperatura e vazão determinadas. Ao se difundir pelo leito, o fluido extrai os componentes solubilizáveis. Nas últimas décadas, as atividades de pesquisa sobre extratos vegetais têm voltado a sua atenção para a utilização do referido processo, especialmente com 
a utilização de dióxido de carbono $\left(\mathrm{CO}_{2}\right)$. Cabe ressaltar que o $\mathrm{CO}_{2}$ é inerte, não tóxico, não inflamável e ainda possui baixo custo (Del Valle et al., 2005).

A macaíba é uma palmeira nativa das florestas tropicais apresentando grande dispersão em quase todo o território brasileiro. Do seu fruto pode-se explorar tanto a polpa como a amêndoa. Segundo Owen et al. (2000), o perfil de ácidos graxos do óleo da polpa é composto principalmente de monoinsaturados, apresentando aproximadamente $73 \%$ de ácido oleico. Devido à grande quantidade de ácidos graxos monoinsaturados apresentados, o óleo da polpa da macaíba assemelha-se ao azeite de oliva, despertando o interesse dos pesquisadores, já que possui componentes importantes no auxílio de doenças hiperlipidêmicas, cardiovasculares e inflamatórias. Além disso, na polpa de macaíba são encontradas concentrações elevadas de carotenóides, os quais são responsáveis pela sua coloração laranja (Rodriguez-Amaya et al., 2008).

Neste trabalho investigaram-se os perfis fitoquímicos de ácidos graxos presentes nos extratos da polpa de macaíba resultante dos processos via fluido supercrítico, a Soxhlet e com emprego do equipamento ASE 350. Os perfis foram obtidos por meio de cromatografia gasosa $(\mathrm{CG})$.

\section{MATERIAL E MÉTODOS}

Os frutos de macaíba são provenientes da região metropolitana do Recife (PE) e foram pesados e despolpados. As polpas foram dispostas sobre uma camada de papel pardo, formando uma única camada e submetidas à secagem em estufa (Luca-82/480) com circulação forçada de ar. As amostras foram secas por aproximadamente $24 \mathrm{~h}$ a $50^{\circ} \mathrm{C}$. Em seguida, foram resfriadas em dessecador, acondicionadas em recipientes plásticos e armazenadas em freezer comercial até o momento dos ensaios.

\subsection{Extração a Soxhlet}

Aproximadamente $30 \mathrm{~g}$ da polpa seca e moída da macaíba foram acondicionadas em cartuchos previamente tarados e submetidas à extração por meio de Soxhlet (Figura 1) utilizando hexano como solvente. A temperatura utilizada foi de aproximadamente $90^{\circ} \mathrm{C}$ e a extração foi realizada por um período total de 4 horas. Ao fim da extração, o solvente foi evaporado por meio de rotoevaporador. $\mathrm{O}$ extrato foi recolhido em frascos âmbar e mantido em freezer a temperatura de $-18^{\circ} \mathrm{C}$ até o momento da cromatografia.

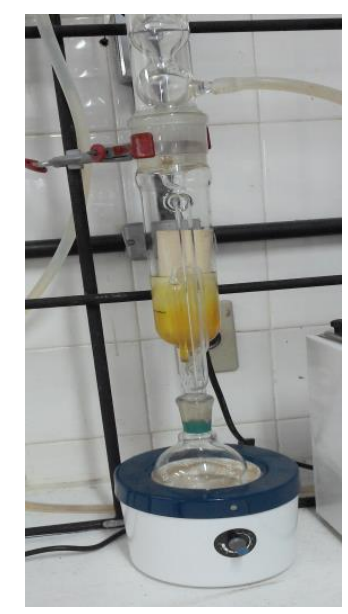

Figura 1 - Extração a quente com o uso de Soxhlet. 


\subsection{Extração Utilizando o ASE 350}

Cerca de $30 \mathrm{~g}$ da polpa seca e moída da macaíba foram homogeneizadas com $15 \mathrm{~g}$ de terra diatomácea. A finalidade desta mistura foi facilitar a transferência de massa dentro do extrator e ainda impedir que a matriz vegetal fosse carreada pelo solvente. Essa mistura foi compactada dentro de um extrator de $14 \mathrm{~cm}$ de altura e diâmetro aproximado de $3 \mathrm{~cm}$. $\mathrm{O}$ extrator foi inserido no equipamento ASE 350 (Figura 2) e as extrações realizadas a temperatura ambiente por cerca de $20 \mathrm{~min}$. O solvente foi evaporado por meio de rotoevaporador e os extratos obtidos foram acondicionados em frascos âmbar e mantidos sob $-18^{\circ} \mathrm{C}$ de temperatura até o momento da realização da cromatografia gasosa.

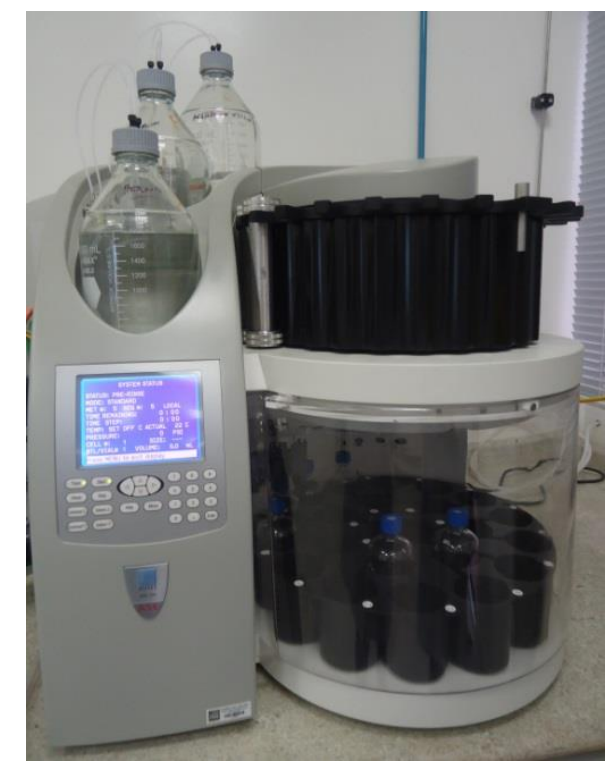

Figura 2 - Equipamento ASE 350.

\subsection{Extração Supercrítica}

Utilizou-se um equipamento de ESC (Figura 3) acoplado a um cilindro de $\mathrm{CO}_{2}$ com tubo pescador. Aproximadamente $40 \mathrm{~g}$ da amostra da polpa seca e moída da macaíba foram compactadas no interior de um extrator encamisado. $\mathrm{O}$ experimento foi realizado a uma temperatura constante de $40^{\circ} \mathrm{C}$ e pressão fixada em100 bar. $\mathrm{O}$ extrato foi recolhido frasco âmbar e acondicionado à temperatura de $-18^{\circ} \mathrm{C}$.



Figura 3 - Equipamento de Extração Supercrítica. 


\subsection{Metodologia Analítica}

O desenvolvimento do método quantitativo de análise por meio de CG foi realizado por padronização externa com o uso de padrão comercial de FAME (Sigma/USA). Aproximadamente $0,5 \mu \mathrm{L}$ das amostras obtidas por meio das técnicas descritas anteriormente foram injetadas em cromatógrafo à gás modelo GC-17A (Shimadzu). A coluna utilizada foi DB-5MS 30m x $320 \mu \mathrm{m} \times 0.25 \mu \mathrm{m}$ (Agilent Technologies). A temperatura inicial do forno foi de $150^{\circ} \mathrm{C}$, com uma isoterma de $4 \mathrm{~min}$ (rampa de $4{ }^{\circ} \mathrm{C} / \mathrm{min}$ até temperatura final de 280 ${ }^{\circ} \mathrm{C}$ ) e uma isoterma de $280{ }^{\circ} \mathrm{C}$ durante $5 \mathrm{~min}$. A razão de Split foi de 100 e hélio foi utilizado como gás de arraste a uma vazão de $2,0 \mathrm{~mL} \cdot \mathrm{min}^{-1}$. As temperaturas do injetor e do forno foram programadas para $300^{\circ} \mathrm{C}$ e $150^{\circ} \mathrm{C}$, respectivamente. O Fluxo de hidrogênio foi de 30 $\mathrm{mL} / \mathrm{min}$, fluxo de ar de $400 \mathrm{~mL} / \mathrm{min}$ e o fluxo de complementação $\left(\mathrm{N}_{2}\right)$ de $25 \mathrm{~mL} / \mathrm{min}$.

As amostras foram submetidas a uma derivatização de ácidos graxos esterificados e livres por método de destilação mista em meio alcalino seguido de um ácido de Lewis.

\section{RESULTADOS E DISCUSSÃO}

As amostras derivatizadas foram submetidas à cromatografia gasosa. Na Figura 4 é apresentado o cromatograma do óleo extraído via Soxhlet utilizando hexano como solvente.

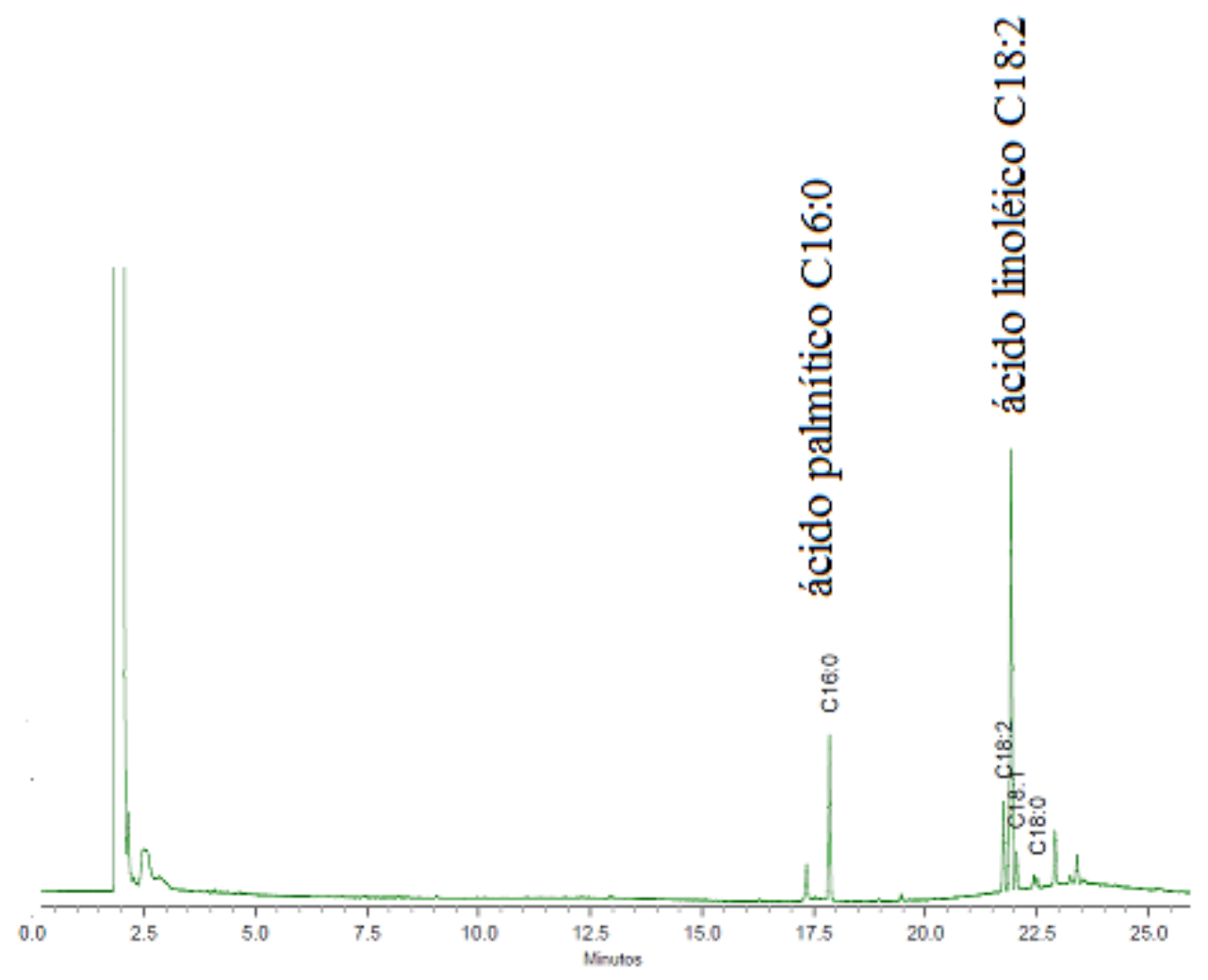

Figura 4 - Perfil cromatográfico da amostra extraída a Soxhlet.

Nas figuras 5 e 6 é apresentado o perfil cromatográfico dos ácidos graxos constituintes das amostras extraídas com o ASE 350 e por via supercrítica, respectivamente. 




Figura 5 - Perfil cromatográfico do extrato via ASE 350.

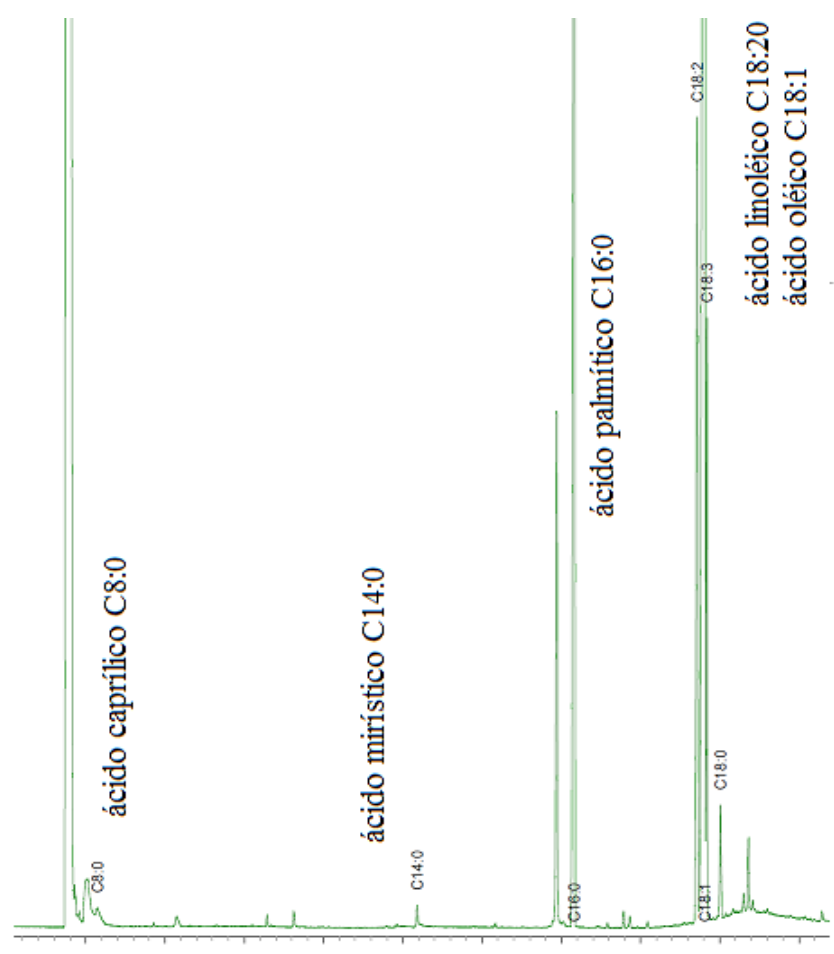

Figura 6 - Perfil cromatográfico do extrato via fluido supercrítico. 


\section{CONCLUSÃO}

Ao fim deste estudo qualitativo pode-se inferir que na análise dos perfis cromatográficos dos extratos provenientes de diferentes técnicas de extração, percebeu-se que o extrato via fluido supercrítico apresentou um número maior de picos, indicando que a técnica de extração utilizada preservou os componentes da polpa de macaíba e comprovando a maior seletividade do $\mathrm{CO}_{2}$.

\section{REFERÊNCIAS}

DEL VAlle, J. M.; DE LA FUENTE, J. C.; CARDARELli, D. A. Contributions to supercritical extraction of vegetable substrates in Latin America. Journal of Food Engineering, v. 67, p. 35-57, 2005.

OWEN, R. W.; GIACOSA, A.; HULE, W. E.; HAUBNER, R.; SPIEGELHALDER, B.; BARSTSCH, H. The antioxidant/anticancer potential of phenolic compounds isolated from olive oil. European Journal of Cancer, v. 36, p. 1235-1247, 2000.

SANTOS, D N. Extração com dióxido de carbono supercrítico e estudo da composição dos extratos de semente de pitanga (Eugenia uniflora L.). Pirassununga: Faculdade de Zootecnia e Engenharia de Alimentos, Universidade de São Paulo, 2012. Dissertação (mestrado).

RODRIGUEZ-AMAYA, D. B.; KIMURA, M.; AMAYA-FARFAN, J. Fontes Brasileiras de carotenóides: Tabela brasileira de composição de carotenóides em alimentos. Brasília: MMA/SBF, 2008. 